\title{
O documentário animado: quando a animação encontra o cinema do real
}

Jennifer Jane Serra ${ }^{1}$

\begin{abstract}
Resumo: Este artigo busca lançar as bases para uma compreensão de como a animação tem dialogado com o cinema documentário por meio do filme híbrido denominado "documentário animado". Abordaremos algumas questões que surgem do encontro entre animação e documentário, apresentando alguns exemplos desse tipo de produção audiovisual.
\end{abstract}

Palavras-chave: documentário animado, cinema não-ficcional, animação.

Abstract: This article expects to understand how animation connects with the documentary film by the hybrid production called "animated documentary". We are going to discuss some issues arising from the meeting between animation and documentary, presenting some examples of this type of audiovisual production.

Keywords: animated documentary, non-fictional cinema, animation. 
Produto da interseção entre documentário e filme de animação, o "documentário animado" está situado na fronteira entre ficção e não ficção e traz aos estudos de cinema questões referentes tanto aos limites dessa demarcação como às possíveis alterações que ocorrem no discurso não ficcional quando o documentário se confronta ou se mistura com outros gêneros cinematográficos. Em paralelo a uma visão restrita de documentário como modo de discurso objetivo sobre o real, a animação esteve fortemente associada ao universo do imaginário desde os primórdios, além de possuir uma natureza não objetiva por sua evidente construção. Esses fatores sublimaram o potencial da animação para tratar de aspectos do mundo real e, ao mesmo tempo, distanciaramna do campo do documentário, ou, de forma mais abrangente, do campo dos discursos não ficcionais. Neste texto, abordaremos algumas questões que surgem do encontro entre animação e documentário, no que se refere ao confronto da primeira com conceitos como realismo, realidade e objetividade, que comumente são associados à definição de filme documentário. Também iremos apresentar algumas definições do objeto documentário animado e exemplos desse tipo de produção audiovisual.

\section{Um breve histórico do documentário animado}

Os primeiros filmes animados surgiram com as produções do cinema mudo, porém, a história da animação começa antes mesmo da invenção do cinema, com as imagens animadas geradas a partir de brinquedos ópticos como o fenaquistiscópio, que está na origem dos primeiros aparelhos cinematográficos. Ele foi inventado pelo físico belga Joseph Plateau e consistia em um disco com desenhos de diferentes fases de um movimento montado sobre um bastão com suporte. Ao girar o disco, produzia-se o efeito do movimento das figuras desenhadas.

Já a relação entre narrativa documental e filme de animação não é algo recente. O pesquisador Paul Wells (1998) utiliza o termo "animação com 
tendência documental", por exemplo, para referir-se à animação que aspira não apenas a uma representação naturalista mas também a um engajamento com a realidade, como o filme de Winsor McCay, The sinking of the Lusitania, de 1918, que é considerado por alguns estudiosos como o "primeiro documentário animado"2. Quando The sinking of the Lusitania foi realizado, a animação já era um campo dominado pela exploração do universo da fantasia, mas a presença do mundo real podia ser sentida em filmes nos quais o animador (ou somente a sua mão) aparecia construindo os personagens e animando-os, como no filme de James Stuart Blackton Humorous phases of funny faces, de 1906.

Em The sinking of the Lusitania, Winsor McCay reconstrói o naufrágio de um cruzeiro britânico que levava cerca de 2.000 pessoas e foi bombardeado por um submarino alemão. Primeiro, o animador é filmado entrevistando uma testemunha e, em seguida, o episódio do naufrágio é reconstruído em desenho animado, com traços realistas que simulam imagens capturadas por uma câmera, ao modo dos jornais cinematográficos. As legendas das cartelas funcionam como um narrador e conectam as imagens ao evento real.

Contemporâneo de Winsor McCay, John Randolph Bray, um dos pais da animação, realizou diversos filmes de animação não ficcional, especialmente por meio da produção de trabalhos educativos e de treinamento. Na Primeira Guerra Mundial, J. R. Bray foi contratado pelo governo americano para produzir curtas de treinamento, e o sucesso foi tanto que ele fez da animação não ficcional o seu grande negócio. Trabalhando para Bray, os irmãos Fleischer criaram e patentearam o processo de rotoscopia em 1917. Esse processo consiste em utilizar a filmagem com atores como referência para construir a animação, de forma que o animador desenha, quadro por quadro, a partir de cada fotograma do filme original. Essa técnica foi bastante utilizada nas produções de Bray e também por Disney, em filmes como Branca de Neve e os sete anões (1937).

Nos filmes de Disney, o processo de rotoscopia foi utilizado como uma das ferramentas para a produção de uma animação que aspirou à verossimilhança 
com o mundo real, ainda que com narrativas de contos de fadas e animais antropomorfos. O interesse de Disney pelo desenvolvimento tecnológico (por exemplo, a adoção do Technicolor - o sistema de três cores e a câmera multiplanos) para tornar mais simples o processo de animação esteve calcado tanto nas suas pretensões de produção industrial como na busca do realismo mimético na animação ${ }^{3}$. Segundo Paul Wells:

\begin{abstract}
Apesar de Disney ter-se relacionado com o que era predominantemente abstrato, não realista, ele insistiu na verossimilhança de seus personagens, contextos e narrativas. Ele queria que figuras animadas se movessem como figuras reais e fossem instruídas por motivação plausível (WELLS, 1998, p. 23).
\end{abstract}

Com suas produções hiper-realistas, Disney ditou os cânones da animação, fazendo que ela fosse compreendida de uma forma limitada, subjugando-a aos aspectos do realismo fotográfico. Como afirma Wells (1998), o domínio de Disney no campo da animação colocou o realismo no centro de qualquer discussão sobre o gênero, e os códigos e as convenções do modelo hiper-realista de Disney passaram a ser utilizados como parâmetros para definir o grau de "realismo" ou de "abstração" de um filme de animação4.

Por outro lado, a produção de filmes de animação no contexto do cinema documentário pode ser vista na própria origem do documentário enquanto um gênero cinematográfico, dentro da produção da escola inglesa de Grierson, nos anos 30. O filme Trade tattoo (1927, Inglaterra), por exemplo, do neozelandês Len Lye, foi realizado quando o animador trabalhava na GPO Film Unit, dirigida por Grierson. A presença da animação em centros de produção do documentário clássico foi mantida no National Film Board do Canadá, onde Grierson fundou um departamento de animação coordenado por Norman McLaren. Gunnar Strøm é um dos pesquisadores que defende essa antiga relação entre animação e documentário: 
Havia uma ligação estreita entre animação e documentário na Europa na década de 1920 (Walter Ruttman, Hans Richter, Dziga Vertov) e no Reino Unido nos anos 30 (John Grierson, Len Lye, Norman McLaren). Essa estreita ligação continuou no National Film Board do Canadá após a Segunda Guerra Mundial e até os dias atuais. Mesmo a Hollywood Academy of Motion Picture Arts and Sciences aceitou o documentário animado como documentário propriamente, dando o Oscar para a McLaren (Neighbours, 1952) e Saul Bass (Why man creates, 1968) (STRøM, 2005, p. 13).

Também durante o período da Segunda Guerra Mundial, a animação não ficcional serviu tanto para instruir a população americana sobre a guerra como para convencê-la da necessidade da entrada do país no conflito. Um dos documentários mais populares nos anos 1940, Why we fight, de Frank Capra, por exemplo, tem partes de animação feitas pela Disney, junto com imagens de arquivo e tomadas da guerra ${ }^{5}$. Os estúdios de Walt Disney produziram também Victory through air power, dos animadores Clyde Geronimi, Jack Kinney, James Alger e H.C. Potter, em 1943, um filme sobre a Força Aérea americana que defendeu os argumentos estratégicos do major Alexander Seversky - que sustentava a adoção de bombardeios de longo alcance, entre outras estratégias militares. Além de Victory through air power, Disney produziu diversos vídeos de treinamento e de cunho militar, como Donald gets drafted, Education for death e Der Fuehrer's face, que tiveram um importante efeito propagandista nos Estados Unidos no período da Segunda Guerra Mundial.

O diálogo do cinema de animação com o campo do discurso não ficcional pode ser reconhecido em grande parte dos filmes educativos e também em produções para relações públicas e propaganda. Nos anos 70, a companhia British Petroleum, por exemplo, patrocinou uma série de animações sobre a evolução do petróleo. Os irmãos animadores Max e Dave Fleischer, inventores da rotoscopia, produziram também obras educativas consideradas documentários científicos, como The Einstein theory of relativity (1923) e Evolution (1925). Além desses, filmes como Down a long way, sobre a busca por petróleo, A for atom, demonstrando a estrutura interna do átomo, e Romance of transportation, do National Film Board, sobre o crescimento do transporte no 
Canadá, ou animações com temas políticos, como as séries Historiebogen (The history book, 1972-1974) and Trællene (The thralls, 1977-80), são exemplos de animações nas quais tanto o conteúdo como os objetivos dos realizadores aproximaram o cinema de animação de documentários, através da proposta de filme educativo e de propaganda.

Segundo Gutar Strøm (2005), no National Film Board, os realizadores não pararam de produzir documentários animados, assim como uma tradição similar foi mantida nos países escandinavos da Dinamarca, da Suécia e da Noruega, com a produção de filmes que vão desde os educativos de Liller Møller e do estúdio Tegnedrengene (The wonderful tale of music, 1991 e World history 1-2, 1993) a filmes para a TV, como Buddy bolden blues (1982). Para Strøm, a produção constante desse tipo de filme nesses países poderia ser explicada pelo pensamento político existente tanto no Canadá quanto na Escandinávia, onde o patrocínio do Estado era essencial para a produção cinematográfica. Além disso, na Escandinávia, a animação foi amplamente utilizada por educadores para tratar de temas considerados "difíceis", como a educação sexual, a exemplo da série de cartoons Sex: a guide for young, de 1987, feita por Liller Møller e pelo produtor Svend Johansen.

Além do Canadá e dos países escandinavos, a Inglaterra também pode ser considerada um dos polos de produção de animação não ficcional. Isso pode ser associado não apenas à relação entre animação e documentário nas produções sob o comando de John Grierson mas também ao espaço dado à animação pelo canal de televisão Channel Four, da rede BBC. Em parceria com o canal, o Estúdio Aardman realizou, nos anos 80, experimentos com animação não ficcional, como a série Conversation pieces (1978-1983), construída a partir da sobreposição do áudio de entrevistas com imagem de bonecos de plastilina, animados com a técnica de stop motion ${ }^{6}$. Também para o Channel Four, foram produzidos, com o formato de curta metragem, documentários de animação de relevância, como $A$ is for autism (1992), de Tim Webb e Silence, de Orly Yadin e Sylvie Bringas?. 
A fórmula de "entrevista animada" usada em Conversation pieces tem sido bastante utilizada até os dias atuais e pode ter tido seus primeiros exemplares em filmes realizados pelo casal americano John e Faith Hubley: em Moonbird (1959), Windy day (1968) e Cockaboody (1972), os animadores retratam as brincadeiras de seus filhos através de desenhos animados, casados com gravações das vozes das crianças. Um dos grandes realizadores desse tipo de produção é o animador Paul Fierlinger, que nos anos de 1980 gravou depoimentos de pessoas sobre assuntos como alcoolismo e solidão e ilustrou as histórias narradas com animação realística. O filme dinamarquês Slaves, de David Aronowitsch e Hanna Heilborn, exibido no festival de documentários É Tudo Verdade, em 2009, pode ser considerado um exemplo mais atual desse tipo de documentário, em que a animação serve de ilustração da banda sonora.

Na década de 1990, o desenvolvimento da computação gráfica impulsionou o uso da animação em filmes documentários, principalmente para a ilustração de mapas e cartelas e para as reconstituições científicas ou históricas. A sofisticação da animação em 3D permitiu à imagem animada alcançar um realismo bastante similar ao das imagens live-action, como pode ser visto em Walking with dinosaurs, realizado pela rede inglesa BBC em 2000, que reproduz a vida dos dinossauros durante a pré-história, exatamente como a ciência afirma ter acontecido.

Lançado em 2004, o filme Ryan, de Chris Landreth, produzido pelo National Film Board, impulsionou a penetração do documentário animado nos circuitos de cinema e de estudos documentaristas. O filme ganhou o Oscar de Melhor Curta de Animação e alcançou projeção internacional. Intitulado como "documentário animado", Ryan conta a história do animador Ryan Larkin através da narrativa em primeira pessoa de Landreth, que também é animador, retratando a meteórica, intensa e importante carreira de Ryan e sua decadência, com seu vício em drogas e álcool. Para construir esse documentário animado, Landreth utilizou o áudio de entrevistas feitas com Ryan e com pessoas ligadas ao animador e a produção de imagens gráficas em 3D, que expressam aspectos 
psicológicos dos personagens e enfatizam a atmosfera e os aspectos emocionais da situação - o que Chris Landreth chamou de "psicorrealismo" (MARTINS, 2009, cap. 8, p. 6). Segundo Fernão Pessoa Ramos, "Ryan é um exemplo claro do que chamamos documentário poético, que utiliza a imagem-câmera, ou se compõe exclusivamente de imagens animadas" (RAMOS, 2008 p. 75).

Nos últimos anos, o documentário animado vem, cada vez mais, sendo pesquisado em centros acadêmicos ${ }^{8}$ e ganhando espaço em festivais, como o Holland Animation Film Festival, que teve esse tipo de produção audiovisual como tema em 2006. Em 2008, a produção israelense Waltz with Bashir, de Ari Folman, foi lançada como o primeiro documentário animado de longa metragem e ganhou diversos prêmios em torno do mundo, como o Globo de Ouro de Melhor Filme Estrangeiro. Waltz with Bashir foi feito a partir dos relatos de ex-combatentes do Exército israelense que lutaram ao lado de Ari Folman na Guerra do Líbano na década de 80. O diretor é um dos personagens e construiu a narrativa do filme a partir de sua busca pelas lembranças esquecidas do massacre no campo de refugiados de Sabra e Shatila.

No Brasil, o documentário animado vem sendo divulgado principalmente pelo festival Anima Mundi, que já teve a presença de realizadores como Chris Landreth e Jonh Cannemaker. Um momento importante de repercussão desse tipo de produção no campo do cinema não ficcional brasileiro ocorreu em 2008, com a participação do curta Dossiê Re Bordosa, de César Cabral, no festival de cinema documentário É Tudo Verdade, no qual recebeu menção honrosa. No ano de 2010, tanto o Festival Anima Mundi como o Festival Internacional de Curtas Metragens de São Paulo contaram com sessões voltadas para esse tipo de produção.

A atual visibilidade do documentário animado dentro do campo do cinema documentário - seja com a sua participação em festivais de documentário, seja através da proliferação de publicações com esse tema ${ }^{9}$ - vem contribuindo não apenas para o crescimento da produção desse gênero de filmes mas também 
para a consolidação do gênero dentro do campo do cinema não ficcional. A importância da aceitação do documentário animado como um tipo de filme documentário se dá, especialmente, por meio da influência dessa aceitação pelo público, pois, quando o filme é rotulado como documentário, o espectador tem em mente que o autor, ou a instituição exibidora, espera que ele veja o filme como um documentário. $\mathrm{E}$ isso é um fator determinante para a leitura fílmica.

\section{Mas afinal... o que é mesmo documentário animado? ${ }^{10}$}

Ao tentar entender o tipo de filme a que estamos nos referindo ao usar o termo "documentário animado", faz-se necessário, primeiramente, considerar o conceito de filme documentário. Para o pesquisador Fernão Pessoa Ramos (2008, p. 22), "documentário é uma narrativa com imagens-câmera que estabelece asserções sobre o mundo, na medida em que haja um espectador que receba essa narrativa como asserção sobre o mundo". Com essa definição, Ramos retoma o conceito de asserção pressuposta, proposto por Noël Carroll, segundo o qual o que caracteriza o documentário é o fato de o espectador pressupor que está articulando asserções verdadeiras ou plausíveis, com base no reconhecimento da intenção assertiva do realizador. Ramos também defende que a imagem-câmera ${ }^{11}$ é a base sobre a qual se sustenta a narrativa documental, mas acrescenta que, no documentário, ela também pode vir acompanhada de imagens de animação.

Em semelhante posição, Bill Nichols (2005) afirma que, diante de um documentário, pressupomos seu status de não ficção e a referência que ele faz ao mundo histórico, ao contrário da ficção, que se refere a um mundo imaginado pelo cineasta. Nichols define o documentário como uma representação do mundo, isto é, um tipo de filme que sustenta um argumento, uma afirmação sobre a sociedade em que vivemos, sendo que essa relação com o mundo histórico é o que o diferencia do filme de ficção. Segundo o autor, no documentário, as situações estão relacionadas no tempo e no espaço em virtude das suas ligações reais, históricas, e não em virtude da trama, como na ficção. 
Em concordância com Fernão Pessoa Ramos e com Bill Nichols, defendemos que o que distingue o filme documentário do filme de ficção é sua proposta como um filme que oferece asserções sobre o mundo através de um discurso, isto é, de uma representação sobre um determinado tema. Também concordamos com Noël Carroll (2005) quando o autor afirma que a distinção entre um filme ficcional e um filme não ficcional não está baseada em elementos manifestos, intrínsecos do filme, como os recursos estilísticos utilizados, mas ela se manifesta através de propriedades relacionais, como a forma como o filme é rotulado pelo realizador.

Nesse sentido, compreendemos que a definição de um filme como "documentário" está baseada no compromisso ou na relação que o filme estabelece com o mundo quando ele reivindica uma abordagem do mundo histórico. Não é, portanto, a utilização de recursos estilísticos próprios da narrativa ficcional (como o uso de atuação ou de animação) ou a ausência de um referente visual do mundo histórico que define o estatuto do filme, mas, como afirma também Carroll, "a distinção entre não ficção e ficção é a distinção entre os compromissos dos textos, não entre as estruturas da superfície dos textos" (BORDWELL \& CARROLL, 1996, p. 287).

Tomando o documentário como um discurso assertivo sobre o mundo em que vivemos, resta diferenciar o documentário animado dos outros tipos de filme documentário, ou mesmo dos outros tipos de filme de animação. Consideramos que somente a presença da animação com um recurso visual do documentário não é suficiente para definir o tipo de filme que classificamos como "documentário animado". Como apontamos anteriormente, muitos documentários fizeram uso da animação desde o início do cinema, como os filmes de propaganda. O que difere o documentário animado é que, nesse caso, o uso da animação está ligado ao tipo de representação que se faz do mundo, e a animação domina toda a narrativa, de maneira que não é possível precisar se o filme pertence ao gênero animação ou ao gênero documentário, mas, antes, os dois estão indissociavelmente misturados (diferentemente dos documentários 
que apresentam apenas trechos de animação, por exemplo). Nesses filmes, o uso da animação se justifica não apenas como um recurso visual, mas pelo fato de a animação ser, ela própria, um recurso de retórica. Consideramos, assim, que, no documentário animado, é por meio da animação que o filme propõe o conteúdo proposicional assertivo, de uma forma que não seria possível através do uso exclusivo de imagens live-action.

Para Sheila Sofian (2005), entretanto, o documentário animado pode ser qualquer filme de animação que se relaciona com material não ficcional, podendo utilizar áudio de entrevistas ou ser a interpretação ou a recriação de fatos. Essa definição poderia ser útil para abarcar os diversos estilos e técnicas de animação, mas, por ser muito ampla, incluiria filmes de animação que não se encaixam no conceito de documentário que adotamos, mas que, de alguma forma, dialogam com o universo não ficcional - como o filme Persépolis (2007), a autobiografia em animação de Marjane Satrapi. Nesse caso, consideramos a lógica informativa que norteia a organização do documentário como um diferencial, em comparação com a estrutura narrativa articulada em torno da trama (que caracteriza a ficção), para diferenciar animações ficcionais sobre fatos ou personagens reais, como Persépolis, daquilo que consideramos ser o documentário animado, isto é, um documentário que, através da animação, oferece um conteúdo proposicional assertivo sobre o mundo real ${ }^{12}$.

A pesquisadora brasileira Índia Mara Martins (2009, cap. 7, p. 8) propõe outra definição para o documentário animado:

\footnotetext{
A princípio, nos parece necessário chamar de documentário animado apenas os filmes de animação que têm algum referente no mundo real, independente da sua forma estética ou estilo. A animação deve ser uma opção de representação consciente em função do potencial visual e narrativo, que se adéqua ao conteúdo apresentado pelo documentário. A animação deve estar amalgamada no conteúdo, e não ser apenas um complemento, uma solução estética.
}

Martins defende a ancoragem em referentes que têm existência no mundo real como base para a sustentação do documentário animado enquanto 
gênero da narrativa documental e o classifica em dois grupos: os filmes que utilizam imagens live-action junto com imagens animadas, e os construídos somente com animação.

Em sua pesquisa, Martins observa que os recursos narrativos utilizados na retórica literária assemelham-se a algumas das estratégias narrativas identificadas por Paul Wells para a animação e formula algumas funções retóricas da animação - que justificariam o seu uso para representar uma dada situação, quando o domínio do campo documental é de produções com imagens de pessoas filmadas:

no caso da inserção de animação em filmes live-action, essa fusão de gêneros não deve ser avaliada apenas pela qualidade técnica da animação e da sua inserção no filme. Mas sim por sua qualidade enquanto função retórica (MARTINS, 2009, cap. 7, p.13).

A autora identifica três funções retóricas da animação no documentário: descrever situações; representar sensações; e estabelecer relações entre situações visíveis e invisíveis. Segundo a autora, são essas funções retóricas que justificam a escolha da animação, e não da filmagem convencional, nos filmes classificados como "documentário animado".

Em sintonia com a proposta de Índia Mara Martins, consideramos que o que justifica essa escolha é o fato de que a animação é uma forma de retórica, isto é, a animação comunica algo através da sua própria natureza idiossincrática, animada. Segundo Paul Ward (2005), a animação diz mais sobre certos aspectos do mundo que as imagens de qualidade fotográfica. Para o autor, a animação é a maneira perfeita de comunicar que há mais da nossa experiência coletiva do mundo do que nossos olhos (ou uma câmera) podem captar. No filme $A$ is for autism, por exemplo, os elementos de composição são trabalhados de forma a representar a realidade particular dos autistas segundo uma linguagem estética que é própria do universo dessas pessoas. A adoção da animação para tratar do autismo permitiu ao diretor realizar uma 
abordagem do assunto que não seria possível com a utilização somente de imagens-câmera. Como afirma Paul Wells sobre o filme:

Cores proeminentes, distorções e omissões em formas representativas, subelaboradas ou figuras e objetos poucos detalhados, ou a mera espontaneidade da linha, tudo revela aspectos de uma condição da qual poucos podem entender ou fazer parte (WELLS, 1998, p. 124-125).

Essa propriedade da animação não se refere apenas à possibilidade de representar visualmente estados mentais ou sentimentos dos personagens mas também ao poder da animação de evidenciar dados ou coisas que estão na atmosfera de uma situação vivida e que somente podem ser sentidos, e não visualizados, porque são aspectos subjetivos dessa realidade. Também os filmes com imagens live-action podem tornar elementos subjetivos, como as sensações dos personagens, perceptíveis através de enquadramentos, de movimentos de câmera e da montagem. Mas, no caso da animação, esses elementos subjetivos são evidenciados e fazem parte do conjunto de asserções dos filmes, como na animação Going equipped (Peter Lord, 1989, Inglaterra). Definida por Wells como um "quase-documentário", Going equipped mistura animação de boneco (feito com plasticina) em stop motion e imagem live-action para ilustrar o depoimento de um presidiário sobre sua infância, seus crimes e a vida na prisão. Nesse caso, a animação é usada para intensificar os gestos e as expressões do personagem, permitindo revelar, através da "performance" do personagem, traços de sua personalidade que não podem ser captados com o áudio da entrevista ou que passariam despercebidos se a imagem fosse a do entrevistado sendo filmado.

\section{Quando o mundo real é representado através da animação}

Quando a animação se relaciona com o documentário, ela pode adquirir uma característica de caráter reflexivo, pois, por mais realista que seja, o espectador sabe que está diante de algo construído, e não diante de um registro do mundo pró-fílmico. Paul Ward (2005) chama a atenção 
para o que ele denomina de "animatedness": a característica da animação de ter a sua "natureza animada" sempre autoevidente, independentemente de quão real ou imparcial seja a realidade ou discurso por ela representado. A animação é um modo de produção essencialmente intervencionista, e não é possível para um documentário animado ser qualquer coisa menos do que um produto visual completamente criado, construído. Essa natureza explicitamente construída da animação entra em conflito com a visão do documentário como sendo um veículo de acesso direto à realidade, ou um relato objetivo sobre o real. Porém, ao contrário de constituir um problema, a natureza contraditória da junção entre animação e documentário permite ao espectador refletir não apenas sobre as asserções que são propostas pelo filme mas também sobre a forma e a abordagem das questões envolvidas nessas asserções, pois ela suscita o questionamento sobre a adequação da representação em relação ao que está sendo representado.

A aparente construção da animação força a reflexão sobre a forma e o significado da representação - algo que se perde na representação mimética oferecida pela imagem fotográfica. O questionamento que o documentário animado suscita, ao contrário de ser um problema, funciona como estímulo à reflexão e pode ressaltar o que está sendo afirmado pelo filme. Segundo Ward (2005), através da dialética particular que é posta em ação ao sabermos que estamos diante do depoimento de uma pessoa real (e o áudio original indexa essa noção) e de uma construção por animação, sem a correspondência indexical a que estamos acostumados a ver em imagens de documentários, a animação pode oferecer um percurso intensificado para entender o mundo social real.

Além disso, essa evidência da natureza construída do documentário animado expõe o realizador, trazendo para o primeiro plano o seu compromisso ético com o sujeito ou com o tema abordado pelo filme. Pela carência de imagens que indexem a realidade representada pela animação, o autor se torna o fiador do discurso apresentado pelo documentário animado e ele tem a responsabilidade 
de representar a subjetividade dos personagens em termos audiovisuais ou de expor dramas e conflitos que requerem certos cuidados quanto à privacidade ou ao anonimato dos entrevistados - como o caso dos filmes da série Animated minds (2003/2008), sobre pessoas com distúrbios psicológicos. Nesse sentido, podemos aproximar o documentário animado dos filmes etnográficos, em relação às questões éticas que esse tipo de produção levanta, especificamente sobre a relação do realizador com o sujeito ou com o assunto do filme.

Nos cinema etnográfico, teóricos, a exemplo da cineasta antropóloga Trinh T. Minh-ha, chamam atenção para a questão de como é construído o discurso sobre aquele "outro" que é representado pelo filme. Quanto à forma de representar um povo ou uma cultura, Trinh T. Minh-ha (CHEN, 1992) defende que a postura do cineasta deve ser a de falar com e, não, falar sobre o outro, isto é, deve utilizar uma fala que não trata do outro como um objeto, como algo distante do enunciador ou ausente do discurso. Uma fala que se reflete nela mesmo, que pertence também a esse outro e que deve materializar-se em todos os aspectos do filme: verbal, musical e visualmente.

Uma das maneiras como essa questão é resolvida pelo documentário animado é através de sua tendência à adoção de métodos de trabalho colaborativos entre o realizador e o sujeito representado no filme. No caso do documentário de animação, os personagens interagem com o animador/cineasta, estando envolvidos na produção. Um exemplo desse processo colaborativo é o filme $A$ is for autism, que utilizou os desenhos dos próprios autistas entrevistados. Além disso, parte das animações do filme fora animada por um dos entrevistados, Daniel Sellers; e o piano da trilha sonora foi executado também por um autista. Exemplos de produções colaborativas como essa são recorrentes, como Abductees (1995, Paul Vester), Pequeñas voces (2003, Eduardo Carrillo) e Silence (1998, Sylvie Bringas e Orly Yadin), entre outros. Outro tipo de produção frequente entre os documentários animados e que alinha realizador e personagem é a autobiografia animada, isto é, o filme de animação que conta a história do 
próprio diretor, como Drawn from memory (1995), de Paul Fierlinger, e Daddy's little bit of Dresden China (1988), de Karen Watson.

Outra questão relevante suscitada pela relação entre animação e documentário é o protagonismo que o áudio desempenha nesse tipo de produção e que não encontra paralelo na maior parte das produções documentárias feitas exclusivamente com imagens live-action. No documentário animado, há um substrato do mundo real que não reside na imagem, mas, sim, no áudio. Esses filmes, frequentemente, usam o áudio real de entrevistas, narrações ou depoimentos que são interpretados criativamente pela parte visual. Uma vez que o espectador está ciente de que o que ele vê é uma construção, ele prontamente passa a refletir sobre a natureza dessa construção (isto é, que tipo de compromisso com o assunto abordado ela segue) e sobre a sua relação com o áudio. Isso é algo quase sempre perdido nos documentários em live-action por causa da relação naturalizada da imagem com o som.

O papel da banda sonora no documentário animado emerge como um elemento fundamental para compreender como o documentário constrói o discurso sobre um determinado assunto e como é posta em ação uma postura assertiva por parte do espectador através do reconhecimento do filme como sendo um documentário, ou, usando os termos de Roger Odin (1984), como uma leitura "documentarisante" do filme é posta em ação. No filme Daddy's little bit of Dresden China, por exemplo, é a combinação da narração em primeira pessoa com uma sequência de fotos da diretora que atesta o filme como uma narração biográfica. Além disso, os comentários masculinos nesse filme são usados para trabalhar a questão do abuso sexual infantil como um fenômeno social, e não particular.

O diferencial da imagem animada no filme documentário diz respeito à tendência da animação à subjetividade, seja no tema, seja na intervenção do animador, o que resulta em uma interpretação assumidamente subjetiva da realidade. Esse tratamento que o documentário animado oferece permite 
explorar a representação visual de sentimentos, pensamentos e visões de mundo dos seus personagens. E a subjetividade está presente no documentário animado não apenas como forma de representar um determinado assunto mas também como tema de alguns desses documentários. Em $A$ is for autism, por exemplo, o objetivo do filme é representar como pessoas autistas veem o mundo, isto é, o tema é a própria subjetividade dos autistas. A natureza do autismo faz que os que têm esse distúrbio percebam o mundo de forma muito particular, que é invisível para quem não é autista. Através da animação, o filme torna visível essa percepção singular do mundo, combinando diferentes intervenções sonoras, falas e efeitos de áudio com recursos visuais, animações de desenhos feitos pelos próprios autistas, montagens sobre imagens filmadas, repetições etc., em um conjunto audiovisual caótico, que corresponderia ao universo mental dos autistas.

A característica dos documentários animados de explorar a subjetividade pode estar relacionada ao contexto do cinema contemporâneo, em que a narrativa é articulada pelo "eu", em que o indivíduo se coloca em cena para falar de algo através de si mesmo. Essas produções, chamadas de "documentário em primeira pessoa", falam sobre si para, eventualmente, fazer asserções sobre questões mais amplas, isto é, para falar sobre o mundo através de um enunciado em primeira pessoa ou mediado pela primeira pessoa. No Brasil, temos exemplos significativos desse tipo de documentário, como os filmes 33 (2003), de Kiko Goifman, e Um passaporte húngaro (2002), de Sandra Kogut.

A exemplo desses filmes, muitos documentários animados são construídos a partir da narrativa em primeira pessoa, para falar tanto de uma situação particular como de uma outra pessoa. Em Daddy's little bit of Dresden China (1988), por exemplo, a animadora Karen Watson reconstrói sua experiência pessoal de ter sido abusada sexualmente pelo pai e tece uma crítica ao modo como o abuso sexual infantil é tratado pelo senso comum. O filme faz uma referência aos contos de fadas e ressalta que as mulheres são representadas de maneira sexualmente predatória na mídia, unindo esferas distantes, como vida 
em família, representações midiáticas, sexo, violência e mitologia infantil, para compor um contexto social - que tem como base sua experiência pessoal. A lista de filmes com o perfil de documentários em primeira pessoa inclui Silence, de Sylvie Bringas e Orly Yadin, o relato de uma sobrevivente de um campo de concentração nazista, Waltz with Bashir, sobre as memórias da guerra no Líbano, de Ari Folman, e a autobiografia de Paul Fierlinger, Drawn from memory.

\section{Conclusão}

O tratamento criativo da realidade operado pelo documentário animado permite que materiais de composição fílmica eminentemente ficcionais, como desenhos, bonecos de plastilina, montagens e computação gráfica, ganhem a textura documental, a ponto de o filme poder ser indexado como documentário. A autoevidência própria da animação está presente também no documentário animado, fazendo que a manipulação ou a construção dos elementos audiovisuais esteja sempre evidente ao espectador. Entretanto, essa natureza claramente construída não anula a asserção que o documentário animado faz sobre o mundo: pelo contrário, ela permite que esse tipo de produção revele mais da realidade de uma situação que um filme produzido com imagens em live-action - pois ela força a reflexão sobre a forma e sobre o significado do que está sendo mostrado.

Além dessa tensão causada pela junção de meios tão distintos, o grande potencial do documentário animado é a capacidade da animação de tornar visíveis as emoções e os pensamentos dos personagens e de ser uma forma de representar a realidade através de seus aspectos subjetivos. Além disso, o engajamento da animação com a narrativa documental, frequentemente associada a conceitos como realismo e objetividade, oferece uma complexidade ao campo do documentário que justifica a sua adoção como estratégia narrativa e torna o documentário animado um interessante objeto para os estudos de cinema. 


\section{Referências}

BORDWELL, D.; CARROLL, N. (Org.). Post-theory: reconstructing film studies. University of Wisconsin Press, 1996.

CARROLL, N. "Ficção, não ficção e o cinema da asserção pressuposta: uma análise conceitual". In: RAMOS, F. P. (Org.). Teoria contemporânea do cinema: documentário e narratividade ficcional, volume 2. São Paulo: Senac, 2005.

CHEN, N. N. "Speaking nearby: a conversation with Trin T. Minh-ha". In: Visual Anthropology Review, 8, n. 1, 1992.

KOTLARZ, I. "Book review: British animation: the Channel 4 factor". In: Animation World Network, fevereiro 2009. Disponível em: <http://www.awn.com/articles/review/bookreview-ibritish-animation-channel-4-factori>. Acesso em: 28 jun. 2010.

MARTINS, I. M. Documentário animado: experimentação, tecnologia e design. Tese (doutorado). Rio de Janeiro: Pontifícia Universidade Católica, 2009.

NICHOLS, B. Introdução ao documentário. Campinas: Papirus, 2005.

ODIN, R. "Film documentaire, lecture documentarisante". In: Cinéma et Réalités. Paris: Cierec, Université de Saint-Étienne, 1984.

RAMOS, F. P. "O que é documentário?" In: CATANI, A.; RAMOS, F. P. (Org.). Estudos de Cinema Socine 2000, Porto Alegre: Sulina, 2001.

. Mas afinal... o que é mesmo documentário? São Paulo: Senac, 2008.

SOFIAN S. "The truth in pictures: explores the multifaceted world of documentary animation". In: FPS Magazine, março 2005. Disponível em: <www.fpsmagazine.com>. Acesso em: 28 jun. 2010.

STRØM, G. "How swede it is... and Danish and Norwegian". In: The Animated Documentary, março 2005. Disponível em: <www.fpsmagazine.com>. Acesso em: 28 jun. 2010.

WARD, P. Documentary: the margins of reality. Londres: Wallflower Paperback, 2005.

"Animated realities: the animated film, documentary, realism". In:

Reconstruction, Studies in Contemporary Culture, 8.2, 2008. Disponível em: <http:// 
reconstruction.eserver.org/082/ward.shtml>. Acesso em: 28 jun. 2010.

WELLS, P. Understanding animation. London, New York: Routledge, Taylor e Francis Group, 1998.

. "Entrando pela porta giratória: o retrato animado da mais antiga profissão por Dave e Alex Beesley". In> Dossier Alexandra \& David Beesley, Associação Cultural VideoBrasil, agosto 2008. Disponível em: <http://www2.sescsp.org.br/sesc/ videobrasil/vbonline/bd/index.asp?cd_entidade=846890\&cd_idioma $=18531>$ Acesso em: 28 jun. 2010.

1 Jennifer Jane Serra é mestranda pelo Programa de Pós-Graduação em Multimeios do Instituto de Artes da Unicamp (Universidade Estadual de Campinas). Email: jennifer.jserra@gmail.com.

2 SOFIAN, Sheila. "The truth in pictures: explores the multifaceted world of documentary animation". In: FPS Magazine, março 2005. Disponível em: <www.fpsmagazine.com>. 
3 Isso incluiu o treinamento intensivo de seus animadores em técnicas para a construção de personagens e de movimentos segundo noções estabelecidas de realismo.

4 Paul Wells chama o realismo de Disney de "hiper-realismo", utilizando-se de um termo de Umberto Eco, definindo-o como o sistema de imagem realística que ecoa o realismo da imagem live-action.

5 Sobre a relação de documentário e animação através do exemplo de Why we fight, ver Fernão Pessoa Ramos, Mas afinal... o que é mesmo documentário? (São Paulo: Senac, 2008, p. 72).

6 Técnica de animação quadro a quadro em que se utiliza uma filmadora ou uma máquina fotográfica ou um computador para captar imagens de objetos, pessoas ou bonecos.

7 Outros exemplos de animações não ficcionais inglesas podem ser conferidos na coletânea do British Film Institute intitulada Real shorts. Mais informações na página do BFI: http://www.bfi.org.uk/education/ teaching/realshorts/.

8 Como os estudos de Paul Ward, na Universidade de Brunel, Inglaterra, de Gunnar Størm, na Suécia, e de Índia Mara Martins, na Pontíficia Universidade Católica do Rio de Janeiro, no Brasil.

9 Por exemplo, a coletânea Animating reality: a collection of short documentaries, uma compilação de documentários animados lançada recentemente pela distribuidora de documentários independentes Ammam (A Million Movies a Minute).

10 Subtítulo inspirado em título do livro Mas afinal... o que é mesmo documentário?, de Fernão Pessoa Ramos.

11 O autor utiliza o termo "imagem-câmera" para designar as imagens em movimento produzidas por aparelhos de filmagem, em contraposição às representações pictóricas.

12 Sobre a lógica informativa do documentário, ver Bill Nichols, Introdução ao documentário, (Campinas, SP: Papirus, 2005), p.73, e Fernão Pessoa Ramos, Mas afinal... o que é mesmo documentário? (São Paulo: Senac, 2008, p. 24-26). 